\title{
Big Data Management and Cloud Computing: Financial Implications in the Digital World
}

\author{
Luminița Ionescu ${ }^{1, *}$, Mihai Andronie ${ }^{1}$ \\ ${ }^{1}$ Spiru Haret University of Bucharest, Department of Economics, Fabricii 46G, 060821, Bucharest, \\ Romania
}

\begin{abstract}
.
Research background: Globalization has had an impact not only on the Internet society, but also on the way in which digital solutions lead to the improvement of the business activity and optimal policies in simple decision-making. Big data, cloud computing and artificial intelligence may essentially improve the company management and the work of the accountants. The increase of sharing information by digital technologies and big data management are opening huge big opportunities and driving investors towards peak globalization.

Purpose of the article: Our aim is to clarify and present the issues in question in terms of financial implications due to the influence of big data management and cloud computing in the digital world.

Methods: Our method to conduct the research is a mix of combining quantitative and qualitative analysis in order to identify the benefits of implementing big data management with positively influences over firms' performance directly.

Findings \& Value added: Our research presents the financial implications of using cloud computing and digital solution for businesses in the digital world, and also the impact study of adopting cloud technology in business development. There are many implications for implementing big data and cloud computing, but the most important one is increasing the productivity of the companies and improving the international economy.
\end{abstract}

Keywords: big data; cloud computing; cloud accounting; artificial intelligence

JEL Classification: $H 12 ; J 21 ; M 15 ; M 48$

\footnotetext{
*Corresponding author: luminitaionescu2003@yahoo.com
} 


\section{Introduction}

Big data management and cloud computing are the most important technologies in the digital world with positive impact on the business organizations and decision-making processes. Big data management is vital for the modern smart sustainable cities in order to accelerate the education development, transportation and mobility in smart cities [1], digital networking, and renewable energy [2]. Big data management has a significant financial implication in the digital world, accelerating the information flow and transmission of data across the Internet, thus improving the quality, accuracy and trustworthiness of the data in the finance industry [3]. Big data is an important trend in financial services, but also in accounting and insurance sectors, not only because of volume of transactions, but also as regards complexity and speed [4, 5]. The current trend of big data management is configured by three important factors [4]:

- Growth in computing power.

- New complex sources of data.

- Modern infrastructure for knowledge creation.

The relationship between big data and cloud computing is strong and complex, but cloud computing provides major solutions for big data $[3,6]$ while accelerating the benefits of digital data management. Big data can be used, reused, moved and modified with low cost at fast speed, bringing about good results for top management.

\section{Methods and Data}

We developed our research based on data collected from Eurostat, Intuit and Software Advice databases. Thus, according to the Eurostat, the use of cloud computing and big data in the EU large companies increased with 21\% during the period 2014-2018, with positive effects for the financial activity. We performed analyses and made some estimates based on the cloud computing for business in European countries and we present the most important benefits and financial implications of big data management in the digital world. Cloud computing is an advanced technology for smart businesses and cloud service models will automate decision making [7-9].

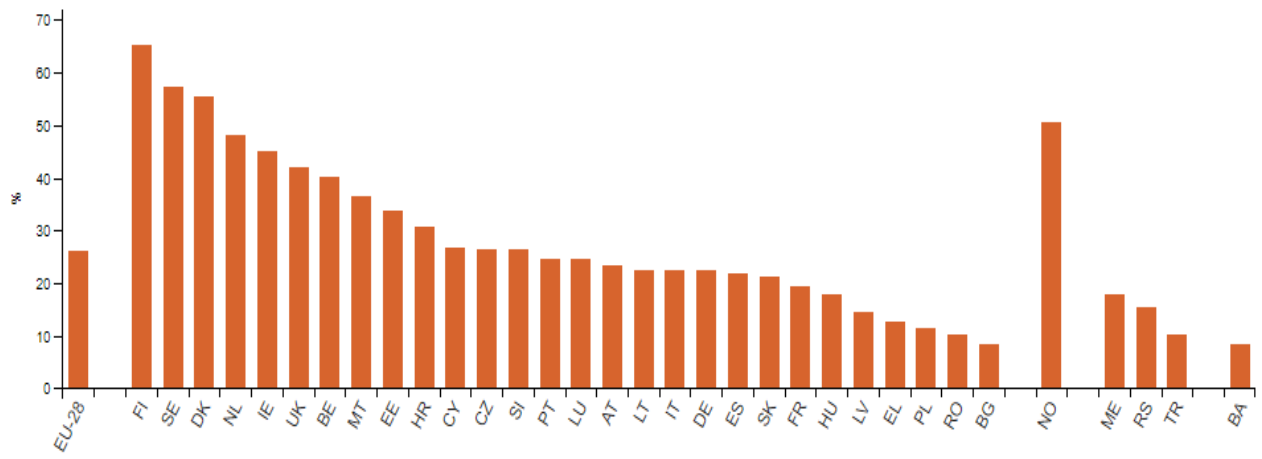

Fig. 1. Use of cloud computing services in 2018

Source: https://ec.europa.eu/eurostat/statistics-explained/index.php?title=Cloud_computing__statistics_on_the_use_by_enterprises (online data code: isoc_cicce_use).

In the last decades two types of cloud models have been implemented by companies to improve big data management: public cloud and private cloud for new and better services to customers $[7,10]$. Both types of cloud models have financial implications for business in the digital world. The most important benefits of cloud model implementation are 
adaptability, flexibility, competitiveness, strong data Security, etc. In the last decades two types of cloud models have been implemented by companies to improve big data management: public cloud and private cloud for new and better services to customers [7, 10]. Both types of cloud models have financial implications for business in the digital world. The most important benefits of cloud model implementation are adaptability, flexibility, competitiveness, strong data security, etc.

Table 1. Use of the public and private cloud

\begin{tabular}{|c|c|c|c|}
\hline & Description & Financial implications & Limitations \\
\hline Public cloud & $\begin{array}{l}\text { Third party service } \\
\text { provider through } \\
\text { the Internet to } \\
\text { deploy IT } \\
\text { solutions suitable } \\
\text { for small } \\
\text { companies }\end{array}$ & $\begin{array}{l}\text {-flexibility of costs } \\
\text {-cost reduction } \\
\text {-data security }\end{array}$ & $\begin{array}{l}\text {-not all controls will be } \\
\text { operated by the institution } \\
\text { itself } \\
\text {-deterioration of service } \\
\text { quality }\end{array}$ \\
\hline Private cloud & $\begin{array}{l}\text { Managed within a } \\
\text { private } \\
\text { organization and } \\
\text { suitable for large } \\
\text { companies }\end{array}$ & $\begin{array}{l}\text {-cost optimization } \\
\text {-flexible budget } \\
\text {-competitiveness allows small } \\
\text { business to act faster than big } \\
\text { companies }\end{array}$ & $\begin{array}{l}\text {-computing resources are } \\
\text { used solely by the one } \\
\text { single organisation }\end{array}$ \\
\hline
\end{tabular}

Source: Authors' own work.

Recently, a hybrid cloud solution has been developed, as an integrated cloud service, using both private and public clouds to perform distinct functions within the same organisation. According to Eurostar, the most uses of cloud computing services are e-mails, office software, storage of files, and hosting the business database.

Table 2. Use of the cloud computing services by email, software, file storage and storage database(s)

\begin{tabular}{|l|c|c|c|}
\hline \multicolumn{1}{|c|}{ Use of the cloud computing services } & \multicolumn{2}{c|}{ Medium } & High \\
\hline e-mail & Yes/No & Yes/No & Yes/No \\
\hline Office software & Yes/No & Yes/No & Yes/No \\
\hline Storage of files & Yes/No & Yes/No & Yes/No \\
\hline Hosting the enterprise's database(s) & No & Yes & Yes/No \\
\hline Financial or accounting software applications & No & No & Yes/No \\
\hline $\begin{array}{l}\text { Customer Relationship Management software } \\
\text { application }\end{array}$ & No & No & Yes/No \\
\hline $\begin{array}{l}\text { Computing power for enterprise's own } \\
\text { software }\end{array}$ & No & No & Yes/No \\
\hline
\end{tabular}

Sources:https://ec.europa.eu/eurostat/statistics-explained/index.php?title=Cloud_computing__statistics_on_the_use_by_enterprises (online data code: isoc_cicce_use).

In a rapidly changing environment, cloud computing and big data are growing fast due to globalization and the Internet society. 


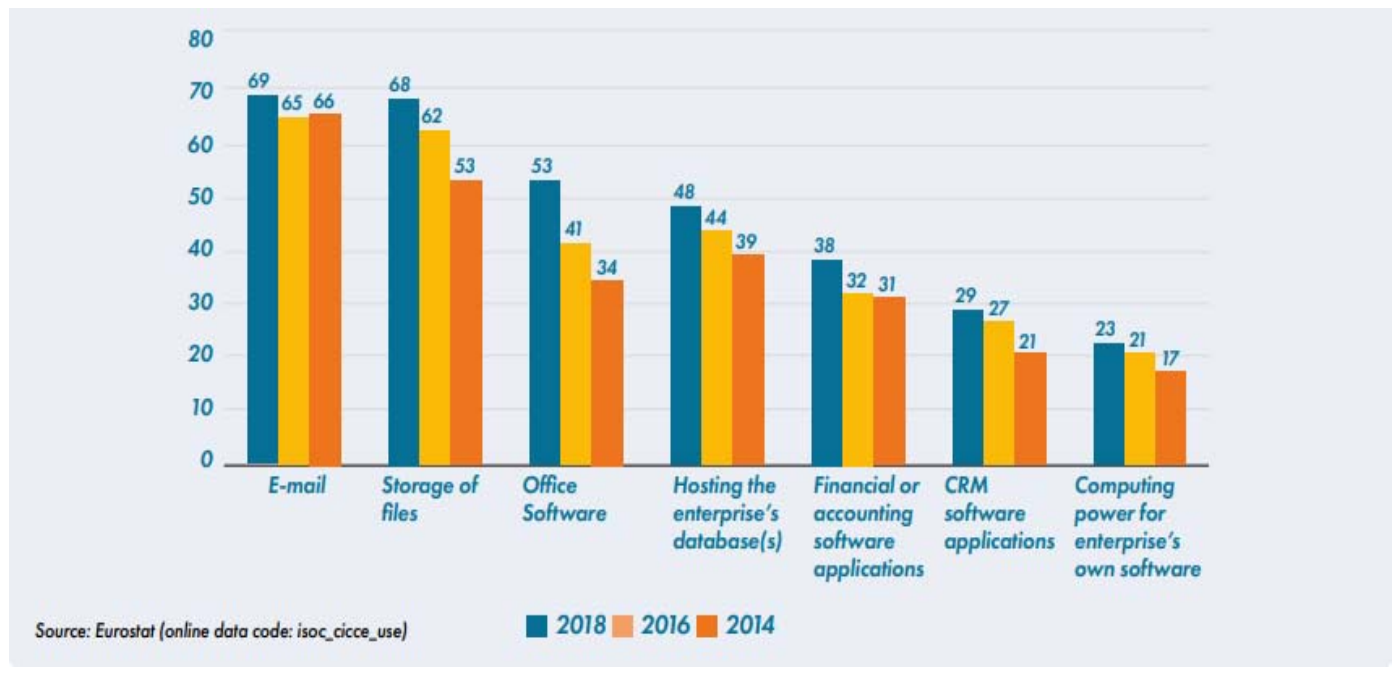

Fig. 2. Use of cloud computing services in enterprises - 2014, 2016 and 2018 (\% of enterprises using the cloud)

Source: https://ec.europa.eu/eurostat/statistics-explained/index.php?title=Cloud_computing__statistics_on_the_use_by_enterprises (online data code: isoc_cicce_use).

\section{Results and Discussion}

Using cloud computing and digital solutions for businesses creates opportunities for increasing specialisation and new opportunities for small businesses. Thus, cloud has become a key technology to develop new financial services and to collaborate with third parties concerning how to compete in the financial sector industries. We present in the table below the key areas where automation technology was implemented in 2019.

Table 3. The key areas where automation technology was implemented in 2019 (\%)

\begin{tabular}{|l|l|}
\hline Finance/Accounting/Auditing & 25 \\
\hline Marketing & 23 \\
\hline Sales & 18 \\
\hline Customer services & 16 \\
\hline Operations & 9 \\
\hline Production & 7 \\
\hline Other & 2 \\
\hline
\end{tabular}

Sources: Intuit and our estimates.

The big companies around the world are adopting modern solutions to implement big data management in order to help the decision-makers to improve the decision-making process [10]. Also, sharing data between firms across the supply chain helps in many aspects development of business plans and aims to achieve the objectives of better firm performance and increasing profits $[11,12]$.

Table 4. Popularity of cloud computing and big data (\%)

\begin{tabular}{|l|l|}
\hline Automation helps improve the customer experience & 61 \\
\hline Automation leads to higher productivity & 59 \\
\hline Automation will enhance knowledge sharing within their organization & 50 \\
\hline
\end{tabular}

Sources: Market Research; our survey among 2,500 individuals conducted July-August 2020. 
Flexibility and data security are imperative for investors and managers, while cloud computing is the technology with the greatest potential to meet both needs. Implementing cloud computing solutions reduce hardware cost and human resources costs, providing numerous tools and expansion opportunities for businesses.

Table 5. Best cloud computing services (\%)

\begin{tabular}{|l|l|}
\hline Google cloud & 78 \\
\hline IBM cloud & 69 \\
\hline Oracle cloud & 71 \\
\hline Others & 50 \\
\hline
\end{tabular}

Sources: Market Research; our survey among 2,500 individuals conducted July-August 2020.

Due to globalization and increasing demand of good quality products, big data management and cloud computing are becoming a new trend among businesses [13]. Using cloud computing services, smart entrepreneurs can develop and launch new products in a short time frame, capitalize on new financial trends, and organize the work of accountants [14]. The adoption of artificial intelligence, robots and big data will increase the profitability of the businesses and improve the international economy [15] while big data can help companies achieve competitive advantage over their rivals [16] and drive investors towards peak globalization. The emergence of data-driven services in the Internet of Things provides manufacturers of technical products with the opportunity to increase their businesses and create jobs [17-19].

Big data is enhancing business value through business intelligence, while big data analytics can assist companies in better exploiting big data for improving customer satisfaction, managing supply chain risk, generating competitive intelligence, and articulating faster decision making [16]. The application of big data and cloud computing in order to improve the financial information provides great value to managers and investors $[9,20]$. Big data brings tremendous promise in the form of exciting innovations, new opportunities and attractive revenue for businesses, greater speed and precision of production $[12,21,22]$.

\section{Conclusions and Implications}

The roles of digital technologies become crucial in extending financial development into new sectors in the wake of the global financial crisis [23]. Big data management and cloud computing are not only a technological trend, but also have significant and positive impact on the financial results of businesses. Cloud computing usage is expanding rapidly and could be the most promising and anticipated technology in the globalization era [24].

Making intelligent decisions requires robust learning ability that explores historical status data and a good management of big data and cloud computing. The most important financial implications of cloud computing are adaptability, cost reductions, and competitiveness, in addition to increasing profitability and efficiency. Big data management can structurally help the majority of businesses shift more gradually into the cloud computing and develop their operations. In our opinion, the benefits of cloud computing are improved efficiency, communication, and resource management, while big data management can structurally facilitate both internal and customer interactions. 


\section{References}

1. Nica, E., Konecny, V., Poliak, M., Kliestik, T. (2020). Big Data Management of Smart Sustainable Cities: Networked Digital Technologies and Automated Algorithmic Decision-making Processes. Management Research and Practice, 12(2), 48-57.

2. Pelton, J.N., Singh, I.B (2019). Smart Cities of Today and Tomorrow: Better Technology, Infrastructure and Security. Springer, Berlin.

3. Yang, C., Huang, Q., Li, Z., Liu K., Hu, F. (2017). Big Data and Cloud Computing: Innovation Opportunities and Challenges. International Journal of Digital Earth, 10(1), 13-53.

4. ICAEW (2019). Big Data and Analytics: The Impact on the Accountancy Profession.

5. Coatney, K. (2019). Cyber-Physical Smart Manufacturing Systems: Sustainable Industrial Networks, Cognitive Automation, and Big Data-driven Innovation. Economics, Management, and Financial Markets, 14(4), 3-29.

6. Zanoon, N., Al-Haj, A., Khwaldeh, S.M. (2017). Cloud Computing and Big Data is there a Relation between the Two: A study. International Journal of Applied Engineering Research, 12(17), 6970-6982.

7. Devasena, L. (2014). Impact Study of Cloud Computing on Business Development. Operations Research and Applications: An International Journal (ORAJ), 1(1), 2-8.

8. Tooby, C. (2019). Governance Mechanisms of Analytical Algorithms: The Inherent Regulatory Capacity of Data-driven Automated Decision-Making. Contemporary Readings in Law and Social Justice, 11(1), 39-44.

9. Furnham, P. (2019). Automation and Autonomy of Big Data-driven Algorithmic Decision-Making. Contemporary Readings in Law and Social Justice, 11(1), 51-56.

10. Mohamad, M., Selamat, A., Krejcar, O., Fujita, H., Wu, T. (2020). An Analysis on New Hybrid Parameter Selection Model Performance over Big Data Set. KnowledgeBased Systems, 192, Art. No. 105441.

11. Gupta, S., Qian, X., Bhushan, B., Luo, Z. (2019). Role of Coud ERP and Big Data on Firm Performance: A Dynamic Capability View Theory Perspective. Management Decision, 57(8), 1857-1882.

12. Trettin, C., Lazaroiu, G., Grecu, I., Grecu G. (2019). The Social Sustainability of Citizen-centered Urban Governance Networks: Sensor-based Big Data Applications and Real-Time Decision-Making, Geopolitics, History, and International Relations, 11(2), 27-33.

13. Lu, Y., Xu, X. (2019). Cloud-based Manufacturing Equipment and Big Data Analytics to Enable on-demand Manufacturing Services. Robotics and Computer-Integrated Manufacturing, 57, 92-102.

14. Ionescu, L. (2019). Big data, Blockchain, and Artificial Intelligence in Cloud-Based Accounting Information Systems. Analysis and Metaphysics, 18, 44-49.

15. Ionescu, L. (2019). Would Taxing the Robots Curtail Technological Advancement or Mitigate the Risks of Automation? Contemporary Readings in Law and Social Justice, 11(1), 33-38.

16. Ram, J., Zhang, C., Koronios, A. (2016). The Implication of Big Data Analytics on Business Intelligence: A Qualitative Study in China. Forth International Conference on Recent Trends in Computers Science \& Engineering, Elsevier, Procedia Computer Science, 87, 221-226. 
17. Anke, J. (2019). Design-integrated Financial Assessment of Smart Services. Electronic Markets, 29, 19-35.

18. Lafferty, C. (2019). Sustainable internet-of-things-based manufacturing systems: industry 4.0 Wireless Networks, Advanced Digitalization, and Big Data-driven Smart Production. Economics, Management, and Financial Markets, 14(4), 16-22.

19. Dubman, R. (2019), The Digital Governance of Data-driven Smart Cities: Sustainable Urban Development, Big Data Management, and the Cognitive Internet of Things. Geopolitics, History, and International Relations, 11(2), 34-40.

20. Liu, X. (2020). Analyzing the impact of user-generated content on B2B Firms' stock performance: Big data analysis with machine learning methods. Industrial Marketing Management, 86, 30-39.

21. Tao, H., Bhuiyan, M.Z.A., Rahman, M.A., Wang, G., Wang, t., Ahmed, M.M., Li, J. (2019). Economic Perspective Analysis of Protecting Big Data Security and Privacy. Future Generation Computer Systems, 98, 660-671.

22. Dolan-Canning, R. (2019). Sensor-based and Cognitive Assistance Systems in Industry 4.0: Big Data Analytics, Smart Production, and Sustainable Value Creation. Economics, Management, and Financial Markets, 14(3), 16-22.

23. Fields, D. (2018). Automated Landlord: Digital Technologies and Post-crisis Financial Accumulation. Environment and Planning A: Economy and Space, 94(2), 118-140.

24. Attaran, M., Woods, j. (2018). Cloud Computing Technology: Improving Small Business Performance Using the Internet. Journal of Small Business \& Entrepreneurship, 31(6), 495-519.

25. Ashander, L., Kliestikova, J., Durana, P., Vrbka, J. (2019). The Decision-Making Logic of Big Data Algorithmic Analytics. Contemporary Readings in Law and Social Justice, 11(1), 57-62. 